\title{
Antibiotic prophylaxis for haematogenous bacterial arthritis in patients with joint disease: a cost effectiveness analysis
}

P Krijnen, C J E Kaandorp, E W Steyerberg, D van Schaardenburg, H J Bernelot Moens, J D F Habbema

Abstract

Objective-To assess the cost effectiveness of antibiotic prophylaxis for haematogenous bacterial arthritis in patients with joint disease.

Methods-In a decision analysis, data from a prospective study on bacterial arthritis in 4907 patients with joint disease were combined with literature data to assess risks and benefits of antibiotic prophylaxis. Effectiveness and cost effectiveness calculations were performed on antibiotic prophylaxis for various patient groups. Grouping was based on (a) type of event leading to transient bacteraemiathat is, infections (dermal, respiratoryl urinary tract) and invasive medical procedures-and $(b)$ the patient's susceptibility to bacterial arthritis which was increased in the presence of rheumatoid arthritis, large joint prostheses, comorbidity, and old age.

Results-Of the patients with joint disease, $59 \%$ had no characteristics that increased susceptibility to bacterial arthritis, and $31 \%$ had one. For dermal infections, the effectiveness of antibiotic prophylaxis was maximally 35 quality adjusted life days (QALDs) and the cost effectiveness maximally $\$ 52000$ per quality adjusted life year (QALY). For other ity adjusted life year (QALY). For other
infections, the effectiveness of prophylaxis
was lower and the cost effectiveness was lower and the cost effectiveness higher. Prophylaxis for invasive medical procedures seemed to be acceptable only in patients with high susceptibility: 1 QALD at a cost of \$1300/QALY; however, the results were influenced substantially when the level of efficacy of the prophylaxis or cost of prophylactic antibiotics laxis or cost
was changed.

Conclusion-Prophylaxis seems to be indicated only for dermal infections, and for infections of the urinary and respiratory tract in patients with increased susceptibility to bacterial arthritis. Prophylaxis for invasive medical procedures, such as dor invasive medical procedures, such as for patients with joint disease who are highly susceptible.

(Ann Rheum Dis 2001;60:359-366)

Correspondence to: Clinical Decision Sciences Clinical Decision Sciences, Health, Erasmus Unive PO Box 1738, 3000 DR Rotterdam, The Nether krijnen@mgz.fgg.eur.nl

Accepted 9 August 2000

Patients with joint disease are at increased ris cocterial arthritis. ${ }^{1-4}$ The come of bacterial arthritis is unfavourable in of causes related to bacterial arthritis, and $25-50 \%$ of the surviving patients suffer from rreversible loss of joint function..$^{5-8}$ Bacterial arthritis is mostly induced haematogenously through the transient spread of bacteria, but can also be caused by direct contamination of the joint-for example, during joint surgery.

As a strategy for preventing bacterial arthritis in joint replacement surgery, antibiotic prophylaxis is common practice in combination with other preventive measures. ${ }^{9}$ Prophylactic use of antibiotics is controversial for events posing a risk of haematogenous bacterial arthritis through transient bacteraemia, such as nvasive medical or dental procedures and infections not involving joints. ${ }^{10-13}$ Prevention frevention of haematogenous bacterial arthritis with antibiotics has been advocated for patients with an increased susceptibility. ${ }^{12-16}$ These include patients with a joint prosthesis suffering from rheumatoid arthritis or diabetes mellitus and those using immunosuppressive medication. Nevertheless, unnecessary use of antibiotics Nevild be avoided, because they can have severe adverse effects such as fatal anaphylactic shock. ${ }^{17}$ The risk of these adverse effects is low, but so is the risk of haematogenous bacterial arthritis for most patients. Moreover, the use of prophylactic antibiotics for commonly occurring events can lead to resistance of bacteria on a population level.

As the incidence of bacterial arthritis is low, randomised controlled trial to study the effects of antibiotic prophylaxis for haematogenous bacterial arthritis is not feasible. For decision making with sparse data on the risks and benefits, decision analysis can be a useful tool. ${ }^{18}$ We used this technique to weigh the risks and benefits of antibiotic prophylaxis for individual patients with joint disease.

\section{Methods}

Data from a prospective study on incidence, risk factors, and outcome of bacterial arthritis in 4907 patients with joint disease in Amsterdam, the Netherlands $\mathrm{s}^{3-5}$ and literature review data were used to assess the risk and outcome of haematogenous bacterial arthritis in several groups of patients with joint disease. The problem was modelled as a decision tree (fig 1). The tree describes the effects of giving and not giving antibiotic prophylaxis to a 60 year old man with joint disease who is confronted with an event posing a risk of haematogenous bacterial arthritis. 
MODEL ESTIMATES

Most of the model estimates were derived from the Amsterdam study. ${ }^{3-5}$ For this analysis, the data for 4907 adult patients with joint disease attending the outpatient clinics for rheumatology were used. In this patient group, the most prevalent joint diseases were osteoarthritis $(40 \%)$ and rheumatoid arthritis $(28 \%)$. Over a period of two years, data were collected prospectively by three monthly questionnaires on the occurrence of bacterial arthritis and risk factors. The case finding in the hospitals was continued for one more year to obtain more patients with bacterial arthritis. Of a total of 37

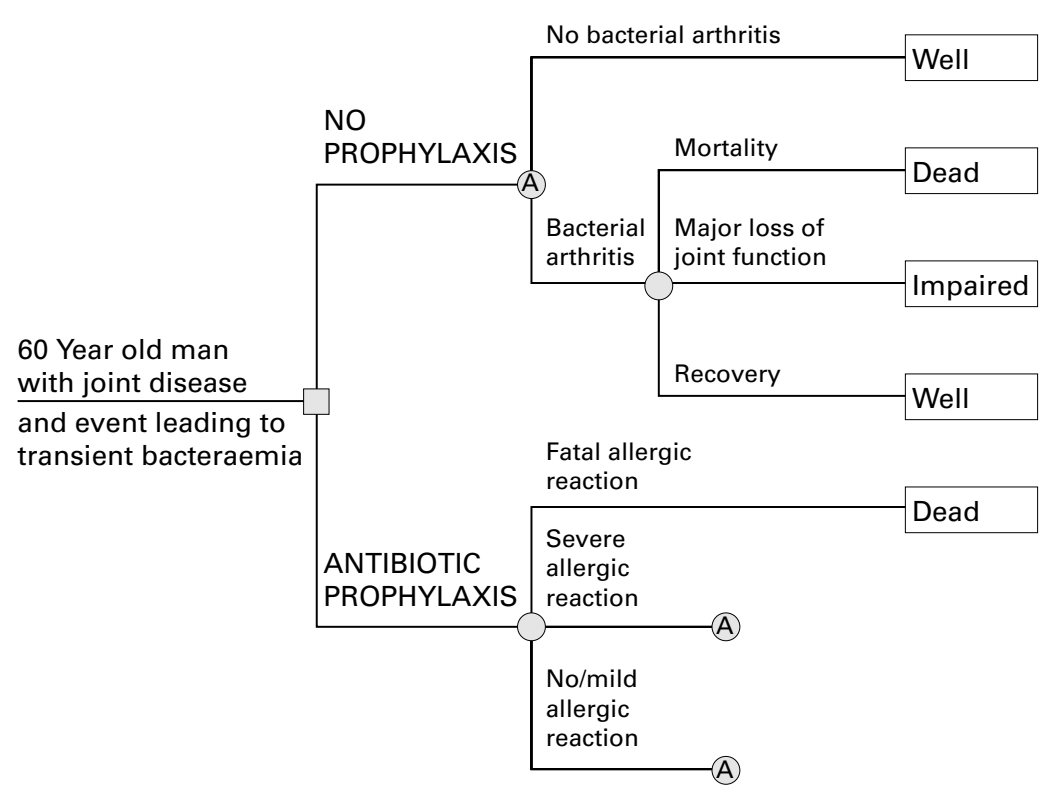

Figure 1 Decision tree for prophylactic management with antibiotics of a 60 year old man with joint disease who is confronted with an event leading to transient bacteraemia. The chronological order of events is from left to right. The decision node is represented by a
square, chance nodes by circles, and health outcomes are indicated by rectangles. Subtree A square, chance nodes by circles, and health outcomes are indicated by rectangles.
is to be inserted in the two lower branches. Quantification of these subtrees differs.

Table 1 Baseline estimates and plausible ranges for model estimates entered into the

\begin{tabular}{|c|c|c|}
\hline & Baseline estimate & Plausible range \\
\hline \multicolumn{3}{|l|}{ Probabilities } \\
\hline Risk of bacterial arthritis & (see table 4$)$ & \\
\hline Efficacy of prophylaxis & $90 \%$ & $45-100 \%{ }^{\star}$ \\
\hline \multicolumn{3}{|l|}{ Risk of reaction to prophylaxis } \\
\hline $\begin{array}{l}\text { Severe, non-fatal reaction } \\
\text { Fatal reaction }\end{array}$ & $0.01 \%$ & $0.005-0.02 \%^{\star}{ }^{\star}$ \\
\hline \multicolumn{3}{|l|}{ Risk of outcome of arthritis } \\
\hline Major loss of joint function & $40 \%$ & 25 to $55 \% \dagger$ \\
\hline Arthritis related mortality & $20 \%$ & 10 to $30 \% \dagger$ \\
\hline \multicolumn{3}{|l|}{ Utilities } \\
\hline Well & 1 & - \\
\hline Impaired & 0.75 & 0.6 to $0.9 \dagger$ \\
\hline & & \\
\hline Discount after non-fatal reaction to prophylaxis & 4 QALDs $\ddagger$ & 2-8 QALDs* \\
\hline \multicolumn{3}{|l|}{ Costs } \\
\hline Recovery from arthritis & $\$ 15000$ & $\$ 7500-30000^{\star}$ \\
\hline Major loss of joint function & $\$ 22000$ & $\$ 11000-44000^{*}$ \\
\hline Arthritis related mortality & $\$ 9000$ & $\$ 4500-18000^{\star}$ \\
\hline (Non)fatal reaction to prophylaxis & $\$ 2000$ & $\$ 1000-4000^{\star}$ \\
\hline \multicolumn{3}{|l|}{ Prophylaxis for } \\
\hline Infection $\$$ & $\$ 60$ & $\$ 30-120^{\star}$ \\
\hline Invasive medical procedure $\|$ & $\$ 12$ & $\$ 6-24^{\star}$ \\
\hline
\end{tabular}

cases, 14 were caused haematogenously. Bacterial arthritis was defined according to the criteria of Newman, ${ }^{19}$ which were modified slightly. Estimates of efficacy and adverse effects of phylaxis were derived from the iterature.

ANTIBIOTIC PROPHYLAX

In accordance with Dutch guidelines, amoxicillin/clavulanic acid was considered to be the antibiotic of choice for preventing bacterial arthritis. ${ }^{16}{ }^{20}$ Prophylactic regimen were: $2000 / 200 \mathrm{mg}$ intravenously before inva( $\mathrm{mg}$ a day rally for 10 days in the case of infection, and once only dose of 3000/750 mg orally before invasive dental treatment. As the efficacy of antibiotic prophylaxis in preventing bacterial arthritis is not known, estimates for endocarditis prophylaxis for patients with valvular heart disease were used as a proxy: the efficacy was disease we side effects of antibiotics was based on dat from the literature: $0.01 \%$ (one in 10000 injections) risk of a severe non-fatal reaction, and $0.002 \%$ (two in every 100000 injections) risk of a fatal reaction. ${ }^{24}{ }^{25}$ These estimates were used for both parenteral and oral administration of antibiotic prophylaxis, alth f adverse reactions to oral adminis of adverse reactions to oral administration is assumed to be somewhat lower. ${ }^{26-28}$

ISK OF BACTERIAL ARTHRITIS

The risk of haematogenous bacterial arthritis was calculated in two steps. (a) On the basis of data from the literature, potential risk events for haematogenous bacterial arthritis were grouped into infections posing a high risk of bacterial arthritis (dermal infections), infections posing a low risk of bacterial arthritis (urinary and respiratory tract infections), and invasive medical procedures (invasive dental treatment and invasive treatment of the skin, ear, nose, throat, gastrointestinal tract, respiratract, urinary tract, and the female genital tract). ${ }^{189121329-31}$ In the prospective study, no antibiotic prophylaxis had been given for these risk events. Questionnaire data from the prospective study were used to calculate the average risk of bacterial arthritis for these three groups of risk events when no antibiotic prophylaxis is given (b) Data on patient prophylaxis is given. (b) Data on patient in a logistic regression model representing the patient's susceptibility to bacterial arthritis. ${ }^{32}$ The patient characteristics studied were established risk factors for bacterial arthritis: presence of knee or hip prosthesis, diagnosis of rheumatoid rthritis, comorbidity (malignancy, diabetes , of 80 years and over, and use of  ward selection was used to discard characteristics not significantly predictive of bacterial arthritis $(p$ to remove $=0.10){ }^{32}$ The fit of the logistic regression model was evaluated by studying the reliability and discriminative ability of the model. The reliability of the model wo the Hosmer-Lemeshow 
of the model was evaluated by the area under the receiver operating characteristic (ROC) curve and its $95 \%$ confidence interval (CI). The risk of bacterial arthritis can be calculated for any patient with specified characteristics given a specified risk event:

$\mathrm{P}($ bacterial arthritis $)=1 /\{1+\exp [-(\alpha+\mathrm{SI})]\}$

where $S I=\beta_{1} X_{1}+\ldots+\beta_{n} X_{n}$. The parameter $\alpha$ is the risk of bacterial arthritis for patients without any of the characteristics studied. For each of the three groups of risk events, $\alpha$ was adjusted by the difference between $\log$ (odds) of the average risk for that group of risk events and $\log$ (odds) of the average risk in the entire patient group. The susceptibility index (SI) reflects the impact of the patient characteristics $(1, . ., n)$ on the risk of bacterial arthritis. $\mathrm{X}$ equals 1 if the risk characteristic is present and 0 otherwise. The logistic regression coefficients for the risk characteristics are represented by $\beta_{1} . . \beta_{n}$. The $95 \%$ CI was calculated for the different levels of risk by correcting the standard error for the smaller number of cases empirically found for each of the risk situations.

EFFECTIVENESS

The effectiveness of antibiotic prophylaxis was expressed as the difference in quality adjusted life expectancy, which is equal to the difference in life expectancy multiplied by the quality of in life expectancy multiplied by the quality of
life. The life expectancy was obtained from the life. The life expectancy was obtained from the years for a 60 year old male patient. Quality of life was expressed on a utility scale, ranging from 0 (dead) to 1 (well). Patients may die from causes related to either bacterial arthritis or antibiotic treatment. Patients were "well" if no bacterial arthritis occurred or after recovery from bacterial arthritis. Further, patients with major loss of joint function due to bacterial arthritis were considered to be in the health state "impaired". Empirical data from the prospective study were used to estimate the utility for the health state "impaired". Patients with major loss of joint function due to bacterial major loss of joint function due to bacterial arthritis described their health state before and Qol questionnaire. ${ }^{36}$ The utility of the health states before and after arthritis were obtained by attaching valuations obtained from the general population to these health state descriptions. ${ }^{38}$ The difference in utility before and after bacterial arthritis for these patients resulted in a utility of 0.75 (95\% CI 0.60 to resulted in a utility of 0.75 ( $95 \%$ CI 0.60 to
0.90 ) for "impaired" (table 1 ). Severe non-fatal $0.90)$ for "impaired" (table 1). Severe non-fatal
side effects of antibiotics were considered to side effects of antibiotics were considered to
cause a loss of 4 quality adjusted life days (QALDs) (plausible range 2-8). These health outcomes were all assumed to occur within one year of receiving prophylaxis or not. On the basis of our prospective study, the risk of basis of our prospective study, the risk of
bacterial arthritis related mortality was estimated to be $20 \%$ (95\% CI 10 to $30 \%$ ), and the risk of major loss of joint function to be $40 \%$ (95\% CI 25 to 55\%)..$^{5}$ After one year, the effects of bacterial arthritis on the health outcome were assumed to be stable, which means that the health states were constant after one year.
We calculated a treatment threshold for the risk of bacterial arthritis to determine which patients may benefit from antibiotic prophyaxis. At this threshold, the quality adjusted life without prophylasis, because the risks and benefits of prophylaxis are exactly balanced. I the risk of bacterial arthritis exceeds the treatment threshold, the benefits of prophylaxis outweigh the risks, and the quality adjusted life expectancy after prophylaxis is higher. Then, prophylaxis is more effective than no prophylaxis.

MEDICAL COSTS

Medical costs were estimated for the first yea after diagnosis of bacterial arthritis from a health care perspective. Through a questionnaire filled out by the 37 patients with bacteria arthritis in the prospective study, an inventory was made of costs due to bacterial arthritis. All we macterial arthritis were calculated up to one year after diagnosis, including costs of hospital stay and medical reatment, cost of physiotherapy, and cost of stay in a rehabilitation clinic or nursing home. Home care was rarely used and therefore not included in the cost calculation. After one year, costs were assumed to be identical for the two costs were based on 1994 Dutch prices and converted into US dollars (Dfl $1=\$ 0.60)$. The average medical cost were $\$ 15000$ after recovery from bacterial arthritis, \$22000 after major joint function oss due to bacterial arthritis, and $\$ 9000$ after bacterial arthritis related mortality (table 1 ). costs of the prescription and pharmacy, were 60 for infections and $\$ 12$ for invasive medical procedures. ${ }^{40}$ The costs of adverse effects of prophylaxis were estimated to be $\$ 2000$. Thi estimate was made by two experienced clinicians, because adverse effects to antibiotics did not occur in our patient group.

COST EFFECTIVENESS

The cost effectiveness was expressed as the costs per quality adjusted life year (QALY) gained by antibiotic prophylaxis for a 60 year old male patient. ${ }^{39}$ Cost effectiveness estimate are presented for infections and invasive medical procedures separately, because the costs of prophylactic antibiotics for these groups of risk events differ.

\section{SENSITIVITY ANALYSIS}

A number of assumptions were made that may influence the results of the decision analysis. In a sensitivity analysis, three questions were addressed. (a) For which risk situations are we certain about the relative effectiveness of prophylaxis? A probable interval for the prophylaxis? A probable interval for the treatment threshold for the bacterial arthritis risk was determined by recomputing the treatment threshold while varying risks and utilities in the model one by one over their full range of plausible values. For model estimates based on empirical data, plausible ranges were defined by the $95 \%$ CIs. For other model estimates, plausible ranges were defined as a half to twice 
Table 2 Average risk of bacterial arthritis in 4907 patients with joint disease after risk events posing a theoretical risk of haematogenous bacterial arthritis through transien
bacteraemia if no antibiotic prophylaxis is given

\begin{tabular}{|c|c|c|c|}
\hline Risk event & $\begin{array}{l}\text { Number of risk } \\
\text { events in } 3 \text { years * }\end{array}$ & $\begin{array}{l}\text { Number of cases } \\
\text { in } 3 \text { years }\end{array}$ & $\begin{array}{l}\text { Average } \\
\text { risk (\%) }\end{array}$ \\
\hline $\begin{array}{l}\text { High risk infection } \\
\text { Skin }\end{array}$ & $\begin{array}{l}7893 \\
7893\end{array}$ & $\begin{array}{l}\mathbf{1 0} \\
10\end{array}$ & $\begin{array}{l}\mathbf{0 . 1 3} \\
0.13\end{array}$ \\
\hline Low risk infection & 22706 & 4 & 0.02 \\
\hline Urinary tract & 3893 & 2 & 0.05 \\
\hline Respiratory tract & 18813 & 2 & 0.01 \\
\hline Invasive medical procedure & 10664 & $\mathbf{0}$ & $\mathbf{0}$ \\
\hline Dental & 6217 & 0 & 0 \\
\hline Skin & 1448 & 0 & 0 \\
\hline Ear, nose, throat & 198 & 0 & 0 \\
\hline Gastrointestinal tract & 1511 & 0 & 0 \\
\hline Respiratory tract & 270 & 0 & 0 \\
\hline Urinary tract & 700 & 0 & 0 \\
\hline Female genital tract & 320 & 0 & 0 \\
\hline
\end{tabular}

follow up assuming that the occurrence of risk events was constant in time.

the baseline value. Uncertainty about the relative effectiveness of prophylaxis remained if the probable interval of the treatment threshold and the $95 \%$ CI for the risk of bacterial arthritis for that situation overlapped. (b) Which factors in the model have a relevant effect on the change in the cost effectiveness results was change in the cost effectiveness results was
assessed by varying model estimates one by one assessed by varying model estimates one by one situations studied. (c) What is the effect of age and sex on the cost effectiveness estimates?

\section{Results}

RISK OF BACTERIAL ARTHRITIS

Ten cases of bacterial arthritis were attributed to dermal infections and four to infections posing a lower risk (two to urinary tract infections and two to respiratory tract infections) (table 2). The average risk of bacterial arthritis was $0.13 \%(95 \%$ CI 0.05 to $0.21 \%)$ after a dermal infection and $0.02 \% \quad(95 \%$ CI 0.0004 to

Table 3 Results of the logistic regression analysis modelling patient characteristics increasing the risk of bacterial arthritis in patients with joint disease

\begin{tabular}{llc}
\hline Patient characteristic & $\beta(95 \% \mathrm{CI})$ & $\begin{array}{c}\text { Coefficient } \\
\text { for index }\end{array}$ \\
\hline Knee/hip prosthesis & $1.9(1.2$ to 2.6$)$ & 2 \\
Diagnosis of rheumatoid arthritis & $1.4(0.6$ to 2.1$)$ & 1 \\
Comorbidity & $1.3(0.4$ to 2.2$)$ & 1 \\
Age of 80 and over & $1.1(0.3$ to 2.0$)$ & 1 \\
& & -+ \\
& & $\mathrm{SI}^{\star}=\ldots$ \\
\hline
\end{tabular}

${ }^{\star}$ The susceptibility index (SI) is the sum of the rounded regre sion coefficients ( $\beta$ ).

Table 4 Risk of bacterial arthritis by susceptibility index (SI) after infections and invasive medical procedures for a 60 year old male patient with joint disease

\begin{tabular}{llll}
\hline & \multicolumn{2}{l}{ Risk of bacterial arthritis in $\%(95 \%$ CI) after a: } \\
\cline { 2 - 4 }$S I^{*}$ & Dermal infection & $\begin{array}{l}\text { Urinary or respiratory } \\
\text { tract infection }\end{array}$ & $\begin{array}{l}\text { Invasive medical } \\
\text { procedure }\end{array}$ \\
\hline 0 & $0.03(0.009$ to 0.1$)$ & $0.004(0.001$ to 0.03$)$ & 0.001 \\
1 & $0.08(0.03$ to 0.3$)$ & $0.01(0.002$ to 0.08$)$ & 0.003 \\
2 & $0.2(0.1$ to 0.6$)$ & $0.03(0.009$ to 0.02$)$ & 0.008 \\
3 & $0.6(0.4$ to 1$)$ & $0.09(0.03$ to 0.4$)$ & 0.02 \\
4 & $2(1$ to 4$)$ & $0.2(0.1$ to 1$)$ & 0.06 \\
\hline
\end{tabular}

The SI is a sum score, based on the presence of a knee/hip prosthesis (2 points), diagnosis of theumatoid arthritis (1 point), comorbidity (1 point), age of 80 and over (1 point) (see table 3 ). Dental, skin, old patient, the SI ranges from 0 to 4 because age does not pose an additional ris the $95 \%$ CI could not be calculated because the risk estimates were not based empirical data.
$0.04 \%$ ) after a low risk infection. No cases of bacterial arthritis were attributed to invasive medical treatment. Therefore the average risk of bacterial arthritis after an invasive medical procedure $(95 \%$ CI 0 to $0.03 \%)$ was estimated to be $0.005 \%$ from literature on antibiotic prophylaxis for invasive dental treatment. ${ }^{41} 42$

In the total group of patients, $13 \%$ had a large joint prosthesis, $28 \%$ were diagnosed with rheumatoid arthritis, 5\% had comorbidity, $6 \%$ were 80 years or older, and $14 \%$ used immunosuppressive medication. In a multivariable logistic regression model, the patient's susceptibility to bacterial arthritis was related to the presence of a knee or hip prosthesis, a diagnosis of rheumatoid arthritis, comorbidity, and age of 80 and over (table 3). For a simple application of the results, the logistic regression coefficients were rounded to integers. The presence of a hip or knee prosthesis was the strongest predictor of bacterial arthritis (regression coefficient $=2$ ). A diagnosis of rheumatoid arthritis, comorbidity, and old age were of similar strength in predicting bacterial The use of mmunosuppressive medication, which was related to all other risk factors except comorbidity, lost most of its predictive value after correction for these risk factors in the model ( $p$ to remove $=0.49$ ). The reliability of the model was good: the probabilities predicted by the model agreed well with the observed frequency of bacterial arthritis $(p=0.84)$. Furthermore, of bacterial arthritis $(\mathrm{p}=0.84)$. Furthermore,
the model discriminated well between cases the model discriminated well between cases was $0.82(95 \%$ CI 0.74 to 0.89$)$. For any patient with a specified combination of characteristics, the SI can be calculated by adding the egression coefficients of the characteristics present, yielding a score ranging from 0 to 5 . For instance, SI $=3$ for an 80 year old patient with osteoarthritis, who has a hip prosthesis but no comorbidity. In our group of patients with joint disease, most patients had low susceptibility to bacterial arthritis: $59 \%$ had ont $0)$. Susceptibility was slightly increased $(\mathrm{SI}=1)$ in $31 \%$ of the patients.

For a 60 year old male patient, the SI ranged from 0 to 4 , because age did not pose an additional risk. Table 4 presents the risk of bacterial arthritis as a function of the SI and of the type of risk event (high/low risk infections and invasive medical procedures) for such a patient. If none of the patient characteristics were present $(\mathrm{SI}=0)$, the predicted risk of bacterial arthritis was $0.03 \%$ after a dermal infection, $0.004 \%$ after a urinary or respiratory tract infection, and $0.001 \%$ after an invasive medical procedure. The presence of patient characteristics, as reflected in the SI, increased the risk of bacas reflected in the SI, increased the risk of bacterial arthritis. Table 4 also shows the $95 \%$ CIs for these risks of bacterial arthritis. CIs for the risk of arthritis after invasive medical procedures could not be calculated because these estimates were not based on empirical data. We assume however, that the risk of bacterial arthritis after an invasive medical procedure is arthritis after an invasive medical procedure is
lower than that after an infection for every level 
Table 5 Effectiveness, costs, and cost effectiveness results by susceptibility index (SI) for a 60 year old male patient with joint disease

\begin{tabular}{|c|c|c|c|}
\hline SI & $\begin{array}{l}\text { Difference in effectiveness } \\
\text { prophylaxis - no prophylaxis } \\
\left(Q A L D s^{*}\right)\end{array}$ & $\begin{array}{l}\text { Difference in costs prophylaxis - } \\
\text { no prophylaxis }(\$)\end{array}$ & $\begin{array}{l}\text { Marginal cost } \\
\text { effectiveness } \\
\left(\$ / Q A L Y^{*}\right)\end{array}$ \\
\hline \multicolumn{4}{|c|}{$\overline{\text { Dermal infections }}$} \\
\hline & 0.4 & 56 & 52000 \\
\hline & 13 & 49 & 14000 \\
\hline 2 & $\begin{array}{l}1.3 \\
3.4\end{array}$ & 31 & 3300 \\
\hline 3 & $\begin{array}{l}.4 \\
10.4\end{array}$ & -30 & \\
\hline 4 & 35.0 & -237 & $t$ \\
\hline \multicolumn{4}{|c|}{ Infections of the urinary tract or respiratory tract } \\
\hline & -0.07 & 59 & \\
\hline & 0.04 & 58 & ${ }_{5}^{+} 50000$ \\
\hline 2 & 0.40 & 56 & 52000 \\
\hline 3 & 1.42 & -47 & 12000 \\
\hline 4 & 3.39 & -31 & 3300 \\
\hline \multicolumn{4}{|c|}{ Invasive medical procedures $\$$} \\
\hline & & 12.10 & $\ddagger$ \\
\hline & -0.07 & 11.80 & \\
\hline & 0.01 & 11.10 & $\stackrel{+}{+} 000000$ \\
\hline & 0.22 & 9.30 & 6000 \\
\hline 4 & 0.91 & 3.20 & 1300 \\
\hline
\end{tabular}

of susceptibility, because bacteraemia after medical procedure is of shorter duration.

EFFECTIVENESS AND COST EFFECTIVENESS

The treatment threshold for the risk of bacterial arthritis was $0.0078 \%$. If the risk of bacterial arthritis exceeded this threshold, the quality adjusted life expectancy with prophylaxis was higher than without prophylaxis and therefore prophylaxis was more effective. This was the case for $(a)$ dermal infections (regardless of the patient's susceptibility to bacterial arthritis), (b) infections of the urinary tract or respiratory tract if the patient's susceptibility is increased (SI $>0$ ), and $(c)$ invasive medical

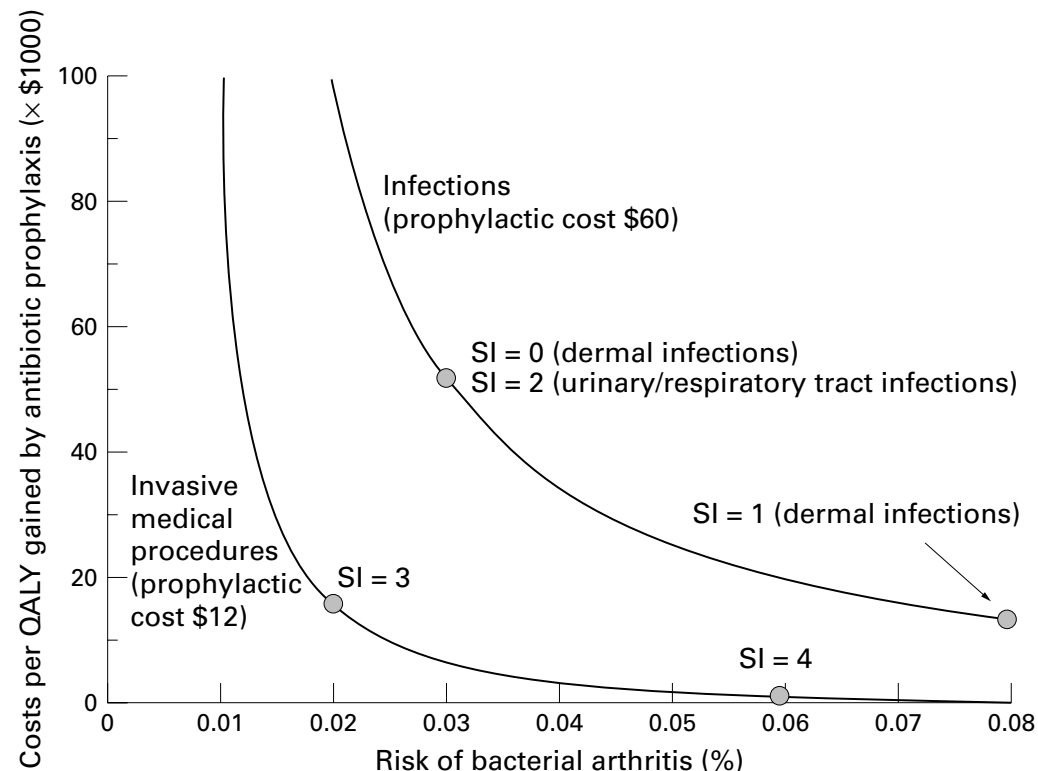

Figure 2 Sensitivity analysis: cost per quality adjusted life year ( $Q A L Y$ ) gained by antibiotic prophylaxis as a function of the risk of bacterial arthritis for infection of the risk situations presented in table 4 , the risk of bacterial arthritis lies within the some depicted range. These risk situations are represented as dots. For example, the risk of bacterial arthritis for patients with low susceptibility to bacterial arthritis $(S I=0)$ was $0.03 \%$ in the case of dermal infection (see table 4). For this risk situation,
prophylaxis costs $\$ 52000$ per $Q A L Y$ gained by prophylaxis (see table 5). procedures only if the patient's susceptibility is moderate or high (SI > 1).

Table 5 presents the quality adjusted life expectancy with and without prophylaxis for al risk situations studied. The benefit of prophylaxis in terms of quality adjusted life expectancy was maximally 35 QALDs in the case of dermal infections, maximally 3 QALDs in the case of infections of the urinary tract and respiratory tract, and maximally 1 QALD in the case of invasive medical procedures.

The costs per QALY gained by prophylaxis varied widely for all types of risk events, depending on the patient's susceptibility (table 5). For dermal infections, the costs amounted to $\$ 52000$ per QALY if the susceptibility was low $(S I=0)$. For patients with high susceptibility $(\mathrm{SI}>2)$, prophylaxis for dermal infections was not only more effective, but also less expensive than no prophylaxis. For infections of the urinary tract and respiratory tract and after invasive medical procedures, the bacterial arthritis risk was lower than for dermal infections. Thus the costs of prophylaxis for these risk events were higher for each level of susceptibility (even though the cost of prophylaxis for medical procedures was lower), amounting to $\$ 1000000$ per QALY. For patients with high susceptibility (SI $>2$ ), the (SI > 2), the pasts per QALY for these events we bly lower: maximally $\$ 12000$ per QALY for respiratory or urinary tract infections, and maximally $\$ 6000$ per QALY for invasive medical procedures.

SENSITIVITY ANALYSES

The treatment threshold for the risk of bacterial arthritis (baseline estimate $0.0078 \%$ ) varied between 0.004 and $0.02 \%$, when the other risk and utility estimates were varied one by one within their plausible range. Given the confidence intervals for the risk of bacterial arthritis as presented in table 4, we were relatively certain that prophylaxis was more effective than no prophylaxis for two situations, even though the exact treatment threshold was unknown: (a) for dermal infections if the unknown: (a) for dermal infections if the and $(b)$ infections of the urinary tract and respiratory tract if the patient's susceptibility was high $(\mathrm{SI}>2)$. For all other risk situations, it was uncertain whether prophylaxis was more or less effective than no prophylaxis.

The cost effectiveness results were influenced most by the risk of bacterial arthritis and by the efficacy and cost of prophylaxis. Figure 2 shows how the costs per QALY varied as a function of the risk of bacterial arthritis, for infections (prophylactic cost \$60) and for invasive medical procedures (prophylactic cost 12) The costs per QALY increased steeply as $\$ 12)$ The costs per QALY increased steeply as the case of infections and below $0.03 \%$ in the case of invasive medical procedures. For risks of bacterial arthritis just above the treatment threshold of $0.0078 \%$, the effectiveness of prophylaxis was infinitely small and therefore the costs per QALY were infinitely high. Furthermore, varying the efficacy and cost of antibiotic prophylaxis within their plausible 
ranges for these low risks of bacterial arthritis had a considerable effect on the cost effectiveness results. For a bacterial arthritis risk after an infection of for instance $0.03 \%$, the costs ranged from $\$ 45000$ to $\$ 170000$ per QALY when we varied the efficacy over its plausible range $(45-100 \%)$. Varying the cost of prophylaxis over its plausible range $(\$ 30-120)$ led to costs of $\$ 24000-110000$ per QALY. For higher risks of bacterial arthritis, the sensitivity to change in these model estimates decreased. For a bacterial arthritis risk of for instance $0.08 \%$ after an infection, the cost ranged from $\$ 12000$ to $\$ 35000$ per QALY when the efficacy was varied, and from $\$ 5300$ to $\$ 31000$ per QALY when the cost of prophylaxis was varied. Uncertainty in the other model estimates influenced the cost effectiveness results to a lesser extent.

Analysis was carried out for a 60 year old male patient. For instance, the cost effectiveness of prophylaxis for a respiratory infection for such a patient with a large joint prosthesis $(\mathrm{SI}=2)$ was $\$ 52000$ per QALY (table 5). Female patients and younger patients benefit more by prophylaxis because they have a longer life expectancy. The cost effectiveness was $\$ 41000$ per QALY for an otherwise similar 60 year old female patient and $\$ 26000$ per QALY for a similar 40 year old male patient. Compared with the 60 year old male patient, older patients have a lower life expectancy on the one hand but a higher risk of bacterial arthritis on the other. For an otherwise similar 80 year old male patient, the cost effectiveness was $\$ 34000$ per QALY.

Discussion

Because of its severe consequences (mortality, morbidity, and loss of joint function), haematogenous bacterial arthritis poses a serious problem for patients with joint disease even though their risk of contracting it is low. According to our analysis, prophylaxis by antibiotic treatment for dermal infections is cost effective for patients with joint disease who have increased susceptibility to bacterial arthritis. For patients with high susceptibility, such as those with both rheumatoid arthritis and a large joint prosthesis, prophylaxis is not only more effective, but also reduces aggregated medical costs. Infections of the urinary tract and respiratory tract were found to pose a lower risk of bacterial arthritis than dermal infections. Prophylaxis for these infections seems to be cost effective only if the patient has relatively high susceptibility to bacterial arthritis. Prevention of bacterial arthritis is an additional argument for antibiotic treatment, which is often given anyway in these patients. The costs for all these risk situations range up to $\$ 14000$ per QALY gained by prophylaxis, which is comparable with other preventive medical interventions in the Netherlands, such as breast cancer screening (about $\$ 5000$ per QALY) ${ }^{43}$ screening for cervical cancer (about $\$ 12000$ per life year), ${ }^{44}$ and cholesterol lowering treatment $(\$ 23000-49000$ per QALY for male patients) ${ }^{45}$ For other risk situations studied in this paper, conclusive evidence for prophylaxis is not found. The cost effectiveness estimates for antibiotic prophylaxis were presented for a 60 year old male patient. Sensitivity analyses showed that the cost effectiveness intes were wot sufficiently so to ustify different recommendations for men and women and for patients of different ages.

The patients with joint disease described in this paper obviously had a high burden of disease, as they were attending an outpatient clinic for rheumatology. Even in this patient group, most had no additional characteristics that most had no addional chacteristics that arthriis. Only $15 \%$ had multiple risk characteristics. Thus only a small group of patients with join disease is highly susceptible to bacterial arthri-

Most studies on the need for antibiotic pophylaxis for bacterial arthritis have investigated patients with joint prostheses, either with or without joint disease ${ }^{10-13} 46$ In contrast, this study was conducted from the perspective of a clinic for rheumatology. All patients with join disease are believed to have an increased risk of bacterial arthritis, and are therefore potential candidates for antibiotic prophylaxis. We did not conduct separate analyses for patients with ond those with only native oints, because we did not have enough patients in each group. We do realise that infected prostheses and infected native joints are no comparable with regard to the inflammator process as well as the treatment options and outcome. Nevertheless, we feel that our decision model gives valid results for both joint prostheses have an in infection and the outcome of bacterial arthritis can be expressed as quality adjusted life expectancy for both groups of patients.

Following Dutch guidelines, we chose amoxicillin/clavulanic acid as the prophylactic antibiotic against bacterial arthritis for all potential sources. Other antibiotics have also been proposed, such as cephalosporins ${ }^{810}$ Unfortunately, it is not known which antibiotic is the best prophylactic. In our sensitivity analysis, a wide range of probable efficacy levels $(45-100 \%)$ was taken into account, showing that a low level of efficacy considerably increased the costs per QALY. Furthermore, cost of prophylaxis is of direct consequence for the the cost of prophylactic cephalosporins is omewhat lower than that of amoxicillin/ clavulanic acid. Assuming an equal level of efficacy, the cost effectiveness of cephalosporins would therefore be slightly more favourable.

Patients with joint disease form a heterogeneous group not only with respect to susceptibility to bacterial arthritis, but also with respect to the disease process and health outcomes. Differences in susceptibility to bacterial arthritis were accounted for in the calculation of the bacterial arthritis risk. Differences with respect to outcome probabilities are also to be tients with rheumatoid arthritis and elderly 
patients have an increased risk of an adverse outcome of bacterial arthritis and are therefore more likely to generate high medical costs. ${ }^{47}$ Such differences were not taken into account, but have only a small effect on the cost effectiveness results according to our sensitivity analysis.

In the decision model, only medical outcomes and costs considered to have a relevant impact on the risks and benefits of antibiotic prophylaxis were included. For instance, mild side effects of antibiotics that do not have a serious impact on the length and quality of life, such as skin rash, were not included in the such as skin rash, were not included in the
model. Considering the age and chronic disease of the patients, indirect costs due to bacterial arthritis were also not included, because production losses due to absence from work were not considered to form a substantial part of the total costs. Although the costs due to bacterial arthritis were somewhat underestimated, it is unlikely that these costs exceeded the upper limit of the plausible range. Sensitivity analyses showed that varying the costs over these ranges of plausible values did not alter the conclusions drawn from the baseline analysis. Further, the time perspective of the study was limited to one year. It was assumed that the health status of most patients was stable one year after diagnosis, and that most of the costs due to bacterial arthritis and side effects of antibiotic prophylaxis had occurred within this period. We do not think it is likely that changes in health outcomes after the first year would have a substantial impact on the results of the study.

Despite the aforementioned limitations, we feel that this analysis increases insight into whether or not to give antibiotic prophylaxis for haematogenous bacterial arthritis to patients with joint disease, because it is based on quantification of benefits and disadvantages of antibiotic prophylaxis with the currently available data. Our analysis suggests that the benefits of antibiotic prophylaxis outweigh its risks in only a limited number of risk situations. In this way, the risk of causing resistance to In this way, the risk of causing resistance to
antibiotics on a population level is minimised. antibiotics on a population level is minimised.
Prophylaxis seems to be indicated only for dermal infections, and for infections of the urinary tract and respiratory tract in patients who have increased susceptibility to bacterial arthritis. Most patients with joint disease do not have risk characteristics that increase their susceptibility to bacterial arthritis. For these patients, bility to bacterial arthritis. For these patients,
antibiotic prophylaxis does not seem to be antibiotic prophylaxis does not seem to be
indicated. Antibiotic prophylaxis for invasive medical procedures, such as dental treatment, may only be indicated for patients with joint disease who are highly susceptible to bacterial arthritis.

We thank M J C Eijkemans for statistical support. This study
was supported financially by the Dutch Prevention Fund (grant

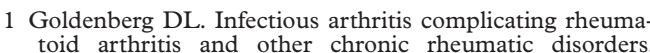
toid arthritis and other chronic hennatic disorders.
Arthritis Rheum 1989:32:496-502.

2 Meijers KAE, Dijkmans BAC, Hermans J, van den Broek PJ., Cats A. Non-gonococcal infectious arthritis: a retro-
spective study. J Infect 1987; 14:13-20.

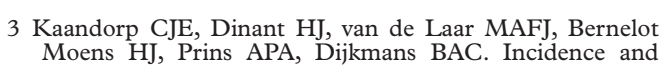
nity based prospective survey. Ann Rheum Dis 1997;56: $470-5$.
Kaandorp CJE, van Schaardenburg D, Krijnen P, Habbem aandorp CJE, van Schaardenburg D, Krijnen P, Habbem
JDF, van de Laar MAFJ. Risk factors for septic arthritis in patients with joint disease. A prospective study. Arthritis Rheum 1995;38:1819-25.
Kaandorp CJE, Krijnen P, Bernelot Moens HJ, Habbem Kaandorp CJE, Krijnen P, Bernelot Moens HJ, Habbema
JDF, van Schaardenburg D. The outcome of bacterial
arthritis, a prospective community-based study. Arthritis Rheum 1997;40:884-92.

DR, Ilstrup DM, van Scoy RE, Washngton JA, Coventry MB. Deep wound sepsis following
total hip arthroplasty. J Bone Joint Surg [Am] 1977;59:

847-55. Carlsson AS, Lindberg L. Hematogenous infec-
Ahlberg A, Cact
tion in total joint replacement. Clin Orthop 1978;137:69-

8 Dubost JJ, Fis I, Soubrier M, Lopitaux R, Ristori JM, Bussiere JL, et al. Septic arthritis in patients with

9 Norden CW. Prevention of bone and joint infections. Am J Med 1985;78 (suppl 6B):229-32. Cawson RA.

Thyne GM, Ferguson JW. Antibiotic prophylaxis during
dental treatment in patients with prosthetic joints. J Bone Joint Surg [Br] 1991;73:191-4.

Blackbur 3 role for prophylaxis. Arthritis Rheum 1991;34:110-17. prevention of late infection of prosthetic joints. Results of 1995;34:380-2.

4 Lattimer GL, Keblish PA, Dickson TB, Vernick CG Wematogenous infection in total join ics. JAMA 1979;242:2213-14.

5 Grant A, Hoddinott C. Joint replacement, dental surgery, and andic prophylaris. BMJ 1992,304:959.

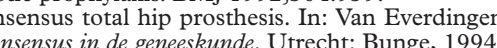
$\mathrm{B} 3 / 1-2$

7 Erffmeyer JE. Adverse reactions to penicillin. Ann Allerg 18 Sox HC, Blatt MA, Higgins MC, Marton KI. Medical decision making. Boston: Butterworth-Heinemann, 1988.

9 Newman JH. Review of septic arthrits through 1988.

N. Amoxycillin pavulanic acid: a review of its efficacy in over 38,500

1 Imperiale TF, Horwitz RI. Does prophylaxis prevent of protective efficacy. Am J Med 1990;88:131-6.

2 Bor DH, Himmelstein DU. Endocarditis prophylaxis fo patients with mitral valve prolapse. A quantitative analysis
Am J Med 1984;76:711-17. Clemens JD, Ransohoff DF. A quantitative assessment of
pre-dental antibiotic prophylaxis for patients with mitravalve prolapse. Journal of Chro Diseses 1984,37:531-

44.
Idsoe O, Guthe T, Willcox RR, de Weck AL. Nature and extent of penicillin side-reactions, with particular reference Organ 1968:38:159-88. in venereal disease clinics. A national survey. JAMA 1973

6 Batson JM. Anaphylactoid reactions to oral administration of penicillin. N Engl J Med 1960;262:590-5.
Toft Sorensen H, Nielsen B, Ostergaard Nielsen J. Anaph lactic 8 Gorevic

Gorevic PD, Levine BB. Penicillin allergy: prediction, prevection, diagnosis, treatment, and

29 Noifect RG. Infecivy Undoc 1985:117 39. pedic and vascular protheses following gastrointestinaPestosc 1990;36:

replacement Terezhalmy GT, Taybos GM. Total joint Oral Surg Oral Med Oral Pathol 1988;66:124-9. thritis. Curr Opin Rheumatol 1993;

32 Hosmer DW, Lemeshow S. Applied logistic regression. New York: Wiley, 1989.

Grogan TJ, Dorey F, Rollins J, Amstutz HC. Deep sepsis
following total knee arthroplasty. J Bone Joint Surg [Am] (96:68:226-34.

4 Ho G.

al arthritis. Curr Opin Rheumatol 1991; 5 Monthly population statistics. Voorburg: Central Bureau of The EuroQol Group. EuroQol - a new facility for the measurement of health-related quality of life. Health Polic

Sonsel GJ, van der Maas PJ. Valuation of health states by the general public: feasibility of a standard-

政


38 Hout BA van, McDonnell J. Estimating a parametric tion using the EuroQol Instrument. In: Björk S, ed. EuroOol Conference Proceedings. Lund (Sweden): Institute for Health Economics, 1992 .
Drummond MF, Stoddart GL, Torrance GW. Methods for the economic evaluation of health care programmes. Oxford: Oxford Medical Publications, 1990.
Onforale Centrale Medisch Pharmaceutische Commissie. Pharmaco-
therapeutical compass 1994 . Amstelveen: Ziekenfondsraad, therapeutical compass 1994. Amstelveen. Ziekenfondsat
1994. of antibiotic prophylaxis for dental procedures in patien Jacobson JI Schweitzer S, DePorter DJ, Lee JJ. Antibie prophylaxis for dental patients with joint prostheses? A
decision analysis. Int J Technol Assess Health Care 1990;6 Koning HJ de, Ineveld BM van, Ootmarssen GJ van, Haes
JCJM de, Collette HJA, Hendriks JHCL, et al. Breast cancer screening and cost-effectiveness; policy alternatives, quality of life considerations and the possible impact of
uncertain factors. Int J Cancer 1991;49:531-7. 4 Koopmanschap MA, Lubbe JThN, Oortmarssen GJ van, Agt HME van, Ballegooyen M van, Habbema JDF.
Economic aspects of cervical cancer screening. Soc Sci
Med 1990:30:1081-7 Med 1990;30:1081-7.
45 Martens LL, Rutten FFH, Erkelens DW, Ascoop CAPL 5 Martens LL, Rutten FFH, Erkelens DW, Ascoop CAPL.
Clinical benefits and cost-effectiveness of lowering serum
cholesterol levels: the case of simvastatin and cholestyramine in The Netherlands. Am J Cardiol 1990;65:27F-
$32 \mathrm{~F}$.

$32 \mathrm{~F}$.
46 Norden CW. Antibiotic prophylaxis in orthopedic surgery. Poss R, Thornhill TS, Ewald FC, Thomas WH, Batte NJ Sledge CB. Factors influencing the incidence and outcom of infection following total joint arthroplasty. Clin Ortho 8 Yu LP, Bradley JD, Hugenberg ST, Brandt KD. Predictors of mortality in non-post-operative patients with septic
arthritis. Scand J Rheumatol 1992;21:142-4. 